\title{
Master training in Agribusiness and Rural Development at the University of Zagreb
}

\author{
László Kárpáti \\ Faculty of Agricultural Economics and Rural Development, University of Debrecen
}

Project title and acronym: Agribusiness Higher EducAtion Development (AHEAD)

Specific objectives of the project: Curriculum Development for Agribusiness as well as Food Safety and Quality in Croatia Development of new BSc and MSc programmes and modernisation of their professional content Retraining of Teaching Staff in Croatia

Type and duration of the project: Curriculum Development, 3 years

Educational institution: University of Debrecen

Partner country universities involved: University of Zagreb

\section{Summary of the main features of the project}

The title of the proposed JEP project is: "Agribusiness Higher EducAtion Development" with the acronym AHEAD. This curriculum development project - in case of acceptance - will last for three years, from July 2005 and June 2008. The primary project site is the University of Zagreb, Croatia; the contractor and the co-ordinator institution is the University of Debrecen, Hungary. In the consortium, 3 further European universities (University of Hohenheim, Wageningen University and Scottish Agricultural College) will participate, from the Croatian side the Ministry of Agriculture, Forestry and Water Management and an additional 7 Croatian institutes will also be involved. The total number of members in the consortium is 13 .
The main objective of the AHEAD project is to establish new BSc and MSc programmes in Croatia at two Faculties of the University of Zagreb. These are as follows: Agricultural and Rural Development, Food Safety and Quality Management and pilot MSc training in Agribusiness and Rural Development. These are preceded by faculty retraining programmes in food safety and quality management, as well as agribusiness and commerce within the framework of a MBA programme accredited by the International MBA Network.

The professional content of the project is a modernised curriculum and training palette that would be available by the end of this project at the University of Zagreb, serving not only the higher education of the country, but the demand of the Croatian national economy as well, in line with the basic principles of the European Union.

Table 1: Members of the consortium

\begin{tabular}{|l|l|l|l|}
\hline First name & Surname & Function & Higher education institution: \\
\hline János & Nagy & Rector & University of Debrecen \\
László & Kárpáti & Vice Dean & University of Zagreb \\
Josip & Juracak & Associate & \\
W. J. M. & Heijman & Professor & Wageningen University \\
Reiner & Doluschitz & Professor & University of Hohenheim \\
David & McKenzie & Vice principal & Scottish Agricultural College \\
Miroslav & Bozic & Assistant minister & Ministry of Agriculture, Forestry and Water Management \\
Josip & Gugic & Assistant & Institute for Adriatic Crops and Karst Reclamation \\
Anita Silvana & Ilak Persuric & Scientific assistant & Institute of Agriculture and Tourism \\
Marina & Miksic & Director's Assistant & Croatian Agricultural Extension Institute \\
Hrvoje & Pokupec & Assistant & "Agrokor" d.d. \\
Sandra & Tankosic & Associate & Croatian Chamber of Economy \\
Lidija & Horvatic & Director & Croatian Employers Association \\
Miroslav & Bajkovec & Secretary & Croatian Society of Agricultural Economists \\
& & & \\
\hline
\end{tabular}




\section{Background of the project}

The Bologna process offers new opportunities for the countries of Europe to think over the structure and professional content of their higher education. The new twostage system of Bachelor and Master trainings gives an opportunity for countries all over Europe to redesign the orientation of trainings, the inner structure and the outcome of their educational activities. In the case of Croatia, it also gives her an opportunity to form new types of training in agriculture and related subjects.

The principal venue of the agricultural training is the Faculty of Agriculture at University of Zagreb, where there is a long tradition of various agriculture-related educational efforts for several decades. Their curriculum has been changed over the decades; however, it has been established that, in its present form, it does not fit the Bologna principles fully. Last year, there was a decision in Zagreb to change agricultural education and for this purpose a reform programme was started in agricultural training with the cooperation of Hohenheim and Vienna Universities, within the framework of a TEMPUS programme. This TEMPUS programme (TEMPUS JEP 17108/2002) opened a new way of thinking at the University of Zagreb, and on its basis, transformed, new Bachelor and Master programmes have been initiated.

In that TEMPUS project, a special emphasis was on the natural sciences and environmental aspects of agriculture. In can be stated, however, that business studies, and especially those which have a special importance for agriculture, did not receive enough emphasis within the programme. In the present situation, agribusiness is a very important part of agricultural training all over Europe, and during the last decade, this area did not receive enough attention in training at the University of Zagreb. Parallel with the accession of Croatia to the EU, more emphasis should be given to the knowledge of agribusiness areas.

Another important area is the food quality problem, which has become the number one question in Europe by now. Consumers want to know how the food that they consume is produced, who is responsible for its quality and especially how safe their food is. In addition to food processing and food technology knowledge and the general characteristics of quality, a special emphasis should be given to the knowledge targeting the evaluation of the critical steps of quality and safety issues of food production. Food quality assurance is also vitally important for the country's accession to the EU. Although the technical knowledge of and the training in these issues are quite developed at the University of Zagreb, it can be stated that so far such a special training was not offered for students.

Following discussions in early 2004 with the university staff of the University of Zagreb, the Faculties of Agriculture, Food Technology and Biotechnology, it can be said that these are the two new areas where more development would be needed. They are also significant due to the application of the Bologna process. Additionally, changes in legislation are certainly needed for Croatia's successful accession to the EU.

These preliminary discussions were fruitful and the decision was made in 2004 at the Faculty of Agriculture to start an Agribusiness and Rural Development Bachelor programme in 2005 , and also a preliminary agreement was achieved together with the Faculty of Food Technology and Biotechnology in order to start a new BSc programme in 2006, in the field of Food Safety and Quality Management. This present TEMPUS application targets especially these two areas, which are full of possibilities not just for the higher education system in Croatia, but also for training experts in this field for the benefit of the whole country.

Rural development is an area which also needs more development in Croatia, since only a first step was made in the education in this field. In the future, this professional area may become one of the most important areas for the country. Knowledge of rural development can be successfully combined with knowledge of agribusiness and such business subjects as Management, Statistics, Mathematics and Operations Research, Marketing, which are very also useful in the field of Food Safety and Quality Management studies. There are also other novelties in the present TEMPUS application, such as cooperation among the Faculties of the University of Zagreb, which was unusual in the past. Another novelty is that some subjects of the Bachelor and Master programmes can also be taught in English, which provides an opportunity to attract foreign students to Zagreb, in addition to delivering up-to-date knowledge to Croatian students who can speak English at appropriate levels. Since the retraining of the University of Zagreb's staff has been a part of this programme and retraining will take place in English language, professional English language education is an embedded part of the programme. This takes place firstly in retraining programmes, and then the university staff will transfer this knowledge to prospective students.

Since the training of Agribusiness and Rural Development as well as Food Safety and Quality Management is quite new in Croatia, it can be stated that experts to be trained are vitally important for the national economy. It can be projected that this training will be prioritized by the government of Croatia. Experts who are badly needed for Croatia in the not too distant future are numbered in thousands, rather than in the hundreds. The establishment of more exact numbers of experts is a part of the programme with the cooperation of the relevant Croatian Ministries and other institutions dealing with this problem.

In summarizing the background of the project, it can be stated that on the basis of the previous TEMPUS project that started in 2003, and the present Council decisions of the University of Zagreb, the necessity of special experts for Croatian national economy in connection with especially the accession to the EU, as well as to the requirements of the Bologna process, show towards the same direction targeted in the present application. It means that the present application can be considered as the continuation of the previous TEMPUS JEP (17108/2002) and will strengthen the University of Zagreb's educational decisions and the human 
resource development plans of the Croatian government as well, all serving the common goals of the European Union.

The Consortium consists of several Central and Western European universities with strong educational potential and wide-ranging international experience, as well as governmental and nongovernmental organisations throughout Croatia, with special expertise in different areas, representing various values that can contribute to the successful completion of the project. Such a composition of the Consortium would mean that the management of the project is not an easy task. However, if effective communication can be facilitated among the Consortium members, then the value that a certain Consortium Member can add to the project could guarantee the generation of a high quality outcome. It is planned, therefore, that an Internet-based communication platform should be set up to guarantee the effective cooperation among the different consortium members and this new method will make it possible to utilise the specific knowledge of each Consortium Member for the benefit of the entire project.

\section{Project description}

The main objective of the AHEAD project is to establish new BSc and MSc trainings in Croatia at the University of Zagreb, namely at two faculties: the Faculty of Agriculture and the Faculty of Food Technology and Biotechnology. The new trainings - that are based on the Bologna principles - are as follows: a 3-year BSc training in Agribusiness and Rural Development, starting in 2005, basically at the Faculty of Agriculture with the cooperation of departments from the other Faculty. The other BSc training, named Food Safety and Quality Management is planned to start in 2006, with the same arrangement as above.

In order to meet the requirements of the national economy of Croatia, a training needs analysis (TNA) is carried out from the beginning of the project: July 2005, in order to know how many experts are needed for these areas in the Croatian national economy in the medium and long runs, with the assistance of the Ministry of Agriculture, Forestry and Water Management as well as the other Croatian Consortium Members working in this field. The trainings are preceded by a retraining programme for the staff of the University of Zagreb. In case of agribusiness and rural development issues, retraining will take place within the MBA training in Agribusiness and Commerce, based on the principles of the International MBA Network. This retraining programme makes the Faculty members capable of teaching the Bachelor and later (in 2007) a pilot Master training in Agribusiness and Rural Development and related studies effectively at the University of Zagreb.

Food Safety and Quality Management training is also preceded by a retraining programme. This programme is provided by the EU university consortium members (Debrecen, Hohenheim, Wageningen, Aberdeen). This programme contributes to the personal professional development of the faculty members of the University of
Zagreb and later makes them capable of teaching these subjects in English, as well. After finishing the MBA retraining programme in 2007, there are two tasks for the Faculty members of Zagreb in this direction. One is to accredit the MBA programme at the University of Zagreb by the International MBA Network Supervisory Board, and based on that to establish their own MBA programme in Agribusiness and Commerce in Croatia. At the same time, the University of Zagreb is starting a so-called pilot MSc programme which can later be a regular Master programme in Agribusiness and Rural Development at the University.

By the end of the AHEAD project, June 2008, there will be at least two new BSc programmes established at the University of Zagreb, Agribusiness and Rural Development, with two outcomes: Agribusiness and Rural Development branches. The decision has to be made during the project duration. The other BSc programme is the Food Safety and Quality Management programme, which can also be shared into two branches by the end of the project. This decision should also be made under the operation of the programme. The University of Debrecen organises the whole project on behalf of the Consortium members and provides English trainings for all the educational activities of the project with the cooperation of Wageningen, Hohenheim and Aberdeen universities in all the areas which were mentioned before.

The Croatian Ministry of Agriculture, Forestry and Water Management, together with the other Croatian consortium members, has a double role in the project. At the beginning of the project, from July 2005 to March 2006, they all work together in the training needs analysis for the Croatian national economy, especially in agriculture, agribusiness and food related areas. They also exercise professional supervision of all the programmes to be established at the University of Zagreb. Supervision regards the direction of the training, its structure, its subject composition as well as its inner content in case of each subject. It means that the requirements of the practice are always taken into account, in all the aspects of educational efforts, in addition to the requirements of the Bologna process and the internationally accepted standards of training and examination. Since the retraining and the MBA courses has been all carried out in English, it guarantees the opportunity to teach some subjects in the BSc and MSc programmes in English by the staff of the University of Zagreb. This can mean a better opportunity for the University of Zagreb to attract foreign students and connect to the European Union's Erasmus and other exchange programmes more effectively.

The coordination and financial arrangement of the entire programme is the responsibility of the University of Debrecen. Since the number of consortium members is quite high, altogether 13, and the tasks to be carried out are also quite extensive, an up-to-date and effective management tool has to be set up just at the beginning of the project execution. An Internet-based communication platform will serve for all the information exchange tasks in the project, including communication towards the Croatian government and the general public, as well. This communication platform itself will also be a great benefit for the whole project. Another 
benefit is that - especially in the retraining parts and the MBA training - in addition to the Faculty members of the University of Zagreb, the experts of the Consortium Members of agribusiness and food processing firms can learn together. In this way, effective interaction between the socalled theoretical and practical experts can be guaranteed, which means a long-term benefit for the whole programme.

The equipment to be purchased would serve the trainings of this project and can also contribute extensively to the modernisation of the training in Zagreb. Most of the activities are carried out in Zagreb, but in a limited way the Zagreb staff members will visit the foreign consortium members, as well, in order to study their work on the spot, especially the methodology and examination of the specific subjects and the organisation of whole courses. The composition of the Consortium Members also serves the dissemination targets of the AHEAD project since these activities will be carried out in the middle, northern and southern parts of Croatia, which will ensure the effective dissemination of the results not just among the Consortium Members, but towards a larger professional general public as well. Since the information about the EU is included in many subjects, the dissemination of this knowledge throughout education directly contributes to the successful accession of Croatia to the European Union, as well. The cooperation between the previously accepted TEMPUS JEP (17108/2002) and this application can guarantee that the changes in agricultural training in a broader sense can achieve a "critical mass", moving from the so-called "traditional" training to newer ones targeting the possible future role of "multifunctional" agriculture. The professional content of the project is a modernised curriculum and the training palette that would be available by the end of this project at University of Zagreb serves not just the higher education of the country, but the demand of the national economy of Croatia, as well, in line with the basic principles of the European Union.

\section{Dissemination}

The principal venue of the dissemination activities is Croatia, but a lot of information will be available for the general public of the other participating countries as well. The principal language of information is Croatian; in the case of other countries English language communication is applied. All the dissemination activities are based on the centralised management information platform, via the Internet. The details of this system are described under the title "Project management" III.5.4. Some parts of this English language platform are available for the general public, which means that this is an automatic, but passive dissemination form. In addition, more active forms are planned using the Croatian language as the means of communication. The main means are as follows:
- Croatian language web sites

- Brochures of the planned study programmes

- Press conferences from time to time

- Participating in educational fairs

- University of Zagreb open days with strong cooperation by the participating faculties and special centres

Possible communication forms on behalf of the participating consortium members, especially:

- Ministry of Agriculture, Forestry and Water Management

- Institute for Adriatic Crops and Karst Reclamation (responsible for Southern Croatia)

- Institute of Agriculture and Tourism (responsible for the Northern part of Croatia)

- Croatian Chamber of Economy (nationwide organisation)

- Croatian Employers' Association (voluntary, nationwide organisation)

- Croatian Agricultural Extension Institute (nationwide, state-run organisation)

The combination of the so called "traditional" and "modern" (Internet-based) information technologies and the bilingual approach will guarantee effective information dissemination for the general public.

\section{Sustainability}

The long-term sustainability of the project results can be guaranteed by the fact that the trainings to be developed fulfil an existing educational gap in Croatia. This can be evaluated from two sides:

- Institutional sustainability: the trainings to be developed fully correspond with the efforts of the University of Zagreb. The launching of the Agribusiness and Rural Development BSc programme has already been decided there and the beginning of Food Safety and Quality Management BSc, as well as Agribusiness MSc programmes, are in the planning phase at the University of Zagreb. The appropriate Ministries fully support these plans, so their long-term sustainability is guaranteed in this way.

- Financial sustainability: in case of the trainings carried out at the University of Zagreb, the education mentioned in the previous point above - will be supported by the Croatian Ministry of Education and Science. Business oriented courses, such as the MBA training, provide such an education form that does not exist in Croatia now. Its long term financial feasibility can be guaranteed by maintaining the quality of the training and the Croatian business community will certainly finance the maintenance of the course after the termination of the project. 


\section{Quality control and monitoring}

Monitoring activities are carried out through an Internetbased management information system. It guarantees the constant tracking of the project. Every quarter of a year, an overall evaluation will take place as a part of the monitoring system. At the end of the first and the second years, a yearly report will be composed and at the end of the third year a final report will be created. Due to the constant supervision of advancement through the computer-based information system, quality control by the project management can be considered as a constant, internal task. The external evaluation of the project activities is carried out by different bodies:

- The MBA training is supervised and finally accredited by the Supervisory Board of the International MBA Network.

- The Bachelor and Master trainings developed will be accredited by the Accreditation Board of the Croatian Ministry of Education and Science.
- The professional content subjects and their suitability to international standards will be supervised by the Educational Committees set up by EU universities.

- The practical usefulness of the subjects will be evaluated by partly the Croatian institutional members of the project, their professional counterparts and especially the professional bodies of Croatian Ministry of Agriculture, Forestry and Water Management.

This combined quality assurance system will guarantee to both international standards and the requirements of the Croatian national economy.

\section{Financing}

The proposed total budget is 531698 EUR, with the contribution of the consortium members (cash and in kind) 31.700 EUR, and the requested Tempus grant is 499.998 EUR. 